\title{
Doenças Sexualmente Transmissíveis: conhecimento, atitudes e comportamento entre os adolescentes de uma escola pública
}

\section{Sexually Transmissible Diseases: knowledge, attitudes and behavior among the teenagers of a public school}

Caroline Reis Gerhardt ${ }^{1}$

Silvana Salgado Nader ${ }^{2}$

Denise Neves Pereira ${ }^{3}$

\section{Resumo}

O objetivo do trabalho foi avaliar o conhecimento de doenças sexualmente transmissíveis (DSTs) em adolescentes de uma escola pública, no município de Canoas, Rio Grande do Sul, comparando as diferenças e semelhanças entre os gêneros. A metodologia utilizada foi estudo descritivo, transversal, de caráter quantitativo, do tipo inquérito. A amostra foi de 221 alunos. $\mathrm{Na}$ análise, foram utilizados os testes o teste $t$-Student, qui-quadrado de Pearson ou Exato de Fisher. As análises foram realizadas no programa SPSS (Statistical Package for the Social Sciences) versão 10.0.

Foram estudados 221 alunos de $7^{\mathrm{a}}$ e $8^{\mathrm{a}}$ séries. Não houve predomínio de gênero (de meninos e meninas). A média de idade foi de 14,4 \pm 1,39 anos. Quanto ao conhecimento dos adolescentes sobre DSTs, 77,4\% responderam que conhecem alguma DST, 20,8\% não o tinham e 1,8\% não responderam; as mais citadas foram Acquired Immunodeficiency Syndrome (Aids), com 91,3\%, 66,7\%, sífilis, e 64,3\%, gonorréia. Quase totalidade da amostra $(93,7 \%)$ respondeu que sabe o significado de DST, e 6,3\% não sabiam. Pode-se evidenciar que a grande maioria recebe informações na escola, com $77,8 \%$, por intermédio de agentes comunitários, com 35,1\%, e por meio da televisão, com 31\%. Quanto ao uso de preservativo masculino, $90,9 \%$ da amostra faz uso deste e 4,5\%, não; $1,5 \%$ nunca usou.

Pode-se concluir, a partir deste trabalho, que a grande maioria dos adolescentes demonstrou conhecimento adequado sobre DSTs. As meninas mostraram ter mais consciência do uso do preservativo, apontando que os meninos têm maior resistência ao seu uso. Isso mostra que há a necessidade de maior conscientização dos meninos, em relação ao uso da camisinha, o que representa, talvez, uma questão sociocultural.

Palavras-chave: Doenças Sexualmente Transmissíveis;

Saúde do Adolescente; Conhecimento; Identidade de

Gênero, Educação Sexual.
Key Words: Sexually Transmitted Diseases;

Adolescent Health; Knowledge; Gender Identity,

Sex Education.

${ }^{1}$ Médica graduada pela Universidade Luterana do Brasil, Médica ESF- Porto Alegre/RS.

${ }^{2}$ Universidade Luterana do Brasil- Professora adjunta de pediatria- mestre em Saúde Coletiva pela Universidade Luterana do Brasil.

${ }^{3}$ Universidade Luterana do Brasil- Professora adjunta de pediatria - doutora em Ciências Medicas: Pediatria pela Universidade Federal do Rio Grande do Sul. 


\begin{abstract}
The aim of this study was to evaluate the knowledge about sexually transmitted diseases (STD) among the teenagers of a public school in the city of Canoas, Rio Grande do Sul, comparing the differences/similarities between the gender.
\end{abstract}

The methodology used was that of a descriptive cross-sectional study of quantitative character, type survey. The sample consisted of 221 students. The data were analyzed using Student's t-test, Pearson's chi-square test or Fisher's Exact Test. The analyses were performed in the SPSS (Statistical Package for the Social Sciences) software, version 10.0 .

Two bundred and twenty one students from the 7 th and 8 th grades were evaluated. None of the gender was predominating. The average age was of $14.4 \pm 1.39$ years. As refers to the knowledge of the teenagers about STDs, $77.4 \%$ declared that they did know something about STD, 20.8\% did not have any information and $1.8 \%$ did not answer; the most cited STDs were Acquired Immunodeficiency Syndrome (AIDS) with 91.3\%, syphilis (66.7\%) and gonorrbea (64.3\%). Almost the entire sample (93.7\%) declared to know the meaning of STD, only $6.3 \%$ did not. It may be concluded that the great majority receives information at school (77.8\%), from bealth agents (35.1\%) and through TV (31\%). With respect to male condom use, $90.9 \%$ of the sample uses the condom, $4.5 \%$ do not and $1.5 \%$ had never used it.

This study allows concluding that the great majority of the teenagers have appropriate knowledge about STDs. The girls showed more conscious of the importance of using a condom, mentioning that the boys tended to resist to its use. This might be indicative of a sociocultural question and of the need to raise the awareness of the boys with regard to condom use.

\section{Introdução}

A expressão doenças sexualmente transmissíveis (DSTs) é usada para descrever as doenças que se disseminam principalmente pelo contato íntimo ${ }^{1}$; englobam uma série de infecções causadas por vírus, fungos, protozoários e bactérias, cuja via preferencial de transmissão é a sexual ${ }^{2}$.

As doenças sexualmente transmissíveis são responsáveis por uma epidemia de grande magnitude e também são uma importante causa de morbimortalidade em todo o mundo ${ }^{2}$, levando a implicações médicas e psicológicas severas para milhões de homens e mulheres ${ }^{3}$. Segundo a Organização Mundial da Saúde (OMS), estimase que 340 milhões de novos casos de sífilis, infecção por clamídia, gonorréia e tricomoníase ocorreram durante todo mundo em 1999 nos homens e nas mulheres ${ }^{3}$.

A adolescência corresponde a um período longo do desenvolvimento humano, que se estende dos 10 aos 19 anos de idade .

A idade (menos de 25 anos) é um dos preditores mais importantes para o uso menos consistente de preservativo, desde a segunda metade dos anos 1990. Sendo assim, a atividade sexual desprotegida e precoce do adolescente é um importante fator de risco para a sua exposição às $\operatorname{DST} \mathrm{Ts}^{5,3,6,7}$.

Portanto, segundo dados do Ministério da Saúde, o segmento dos mais jovens compreende um dos grupos mais expostos ao Human Imunodeficiency Virus (HIV): esta é a faixa etária na qual encontramos também a maior proporção dos que mantêm maior número de parceiros eventuais, sem usar camisinha consistentemente ${ }^{6}$.

Esta faixa etária é de grande vulnerabilidade pelas suas características próprias, pela inexperiência que os jovens têm de lidar com os seus próprios sentimentos e com o sentimento do parceiro(a); por nem sempre, possuírem habilidades necessárias para a tomada de decisões e serem responsáveis por elas ao se envolverem em relacionamentos afetivos e sexuais ${ }^{8}$.

Aproximadamente 25\% das DSTs são diagnosticadas em jovens com menos de 25 anos. Os dados disponíveis em âmbito mundial revelam que mais de 30\% das adolescentes sexualmente ativas têm teste positivo para clamídia, e que aproximadamente $40 \%$ foram infectadas pelo papilomavírus humano (HPV). A infecção por gonorréia aumentou em mais de 50\%, sendo que os índices de infecção por gonorréia nos intervalos entre 15 e 19 anos são os maiores, comparados com outras faixas etárias, e mais de 25\% dos casos novos de infecção pelo HIV ocorreram entre jovens menores de 22 anos $^{2}$. 
Existem poucas informações sobre a prevalência de DSTs, já que as únicas de notificação compulsória são sífilis e a Aids 6 .

A prevenção e o controle das DSTs devem ter base em princípios, como a educação, principalmente.

Os últimos dados oficiais indicam que Aids/DST continuam a se expandir rapidamente entre as mulheres e entre os jovens de 15 a 19 anos, grupo em que homens e mulheres são contaminados na mesma proporção ${ }^{6}$.

No âmbito da antropologia, o que é ser homem e/ ou mulher tem suscitado inúmeras interpretações em diversos campos do saber. A atitude dos homens e das mulheres está intimamente ligada às representações simbólicas de masculinidade e feminilidade que se constroem historicamente, são mutáveis e relacionais?.

A vulnerabilidade feminina também fica evidente em relação às DSTs. A identificação tardia das DSTs pode acarretar complicações para a saúde. Além disso, o modo sutil como as DSTs se manifestam em algumas mulheres tornam-nas muito mais difíceis de serem detectadas que nos homens. Tanto a prevenção quanto o tratamento esbarram em questões culturais e de gênero, ainda difíceis de serem trabalhadas ${ }^{8}$.

Em se pensando em adolescentes, esta vulnerabilidade é agravada, também pelas atribuições do ser mulher em nossa sociedade. Assim, enquanto as meninas e as mulheres se tornam mais vulneráveis, por terem sido socializadas a acreditarem numa forma de amor - doação, na qual a entrega deve ser absoluta e a confiança não poderá ser questionada -, por outro lado, os meninos e os homens têm na própria definição de que ser homem é ser viril, vencer desafios, correr riscos e não demonstrar seus sentimentos, o seu fator de fragilidade $^{8}$.

Diante deste antagonismo e dos novos dados da contaminação, talvez seja o momento de repensarmos nossas práticas educativas.

Além dos aspectos epidemiológicos, a prevenção das DSTs envolve também questões socioculturais e psicoafetivas ${ }^{10}$.

\section{Objetivo}

Investigar conhecimento, atitudes, comportamento, transmissão em relação às doenças sexualmente transmissíveis numa população de adolescentes, comparando as diferenças/semelhanças entre os gêneros.

O conhecimento das DSTs é importante para a prevenção destas doenças, pois, por meio dele, estaremos promovendo saúde básica.

A adolescência é uma fase de consolidação de princípios e de aprendizado mais intenso, sendo a escola um veículo de educação. Seu papel é fundamental na intervenção, com profissionais adequados e corretamente instruídos, para acrescentar aos adolescentes conhecimentos sobre DSTs.

Sendo assim, este trabalho se justifica à medida que visa a identificar melhor o conhecimento que os estudantes de Ensino Médio têm a respeito das DSTs.

\section{Materiais e Método}

Realizou-se um estudo descritivo, transversal, do tipo inquérito, que inclui alunos de $7^{\mathrm{a}}$ a $8^{\mathrm{a}}$ séries da Escola Municipal Thiago Würthi, em Canoas, Rio Grande do Sul, Brasil. Havia, nas sétima e oitava séries, 407 alunos matriculados. Destes, 221 adolescentes participaram do estudo. Critérios de inclusão foram os alunos matriculados e cursando as $7^{\text {a }}$ e $8^{\text {a }}$ séries da Escola Municipal Thiago Würthi, que estavam presentes nas aulas em que foi aplicado o instrumento e que aceitaram responder ao mesmo, em que os pais ou responsáveis permitiram a participação no estudo. Critérios de exclusão foram aqueles em que pais ou responsáveis não autorizaram a pesquisa, ou o adolescente que, mesmo sendo autorizado pelo responsável, não teve vontade de fazê-lo; também, o adolescente que não estava presente em sala de aula no momento da aplicação do instrumento ou os alunos que não estavam matriculados na $7^{a}$ ou $8^{a}$ série pela manhã na Escola.

$O$ instrumento da coleta de dados utilizado na pesquisa foi um questionário auto-aplicável, pré-codificado, anônimo, desenvolvido pelos autores, com base no questionário utilizado pelo Ministério da Saúde (Pesquisa 
Conhecimento Atitude Prática ${ }^{11}$. Foi composto por seções com perguntas sociodemográficas, reprodutivas, comportamentais, conhecimento sobre transmissão e prevenção de DSTs, e sobre o uso do preservativo masculino. Os questionários foram entregues aos alunos em envelopes fechados, numerados, aplicados em sala de aula durante o período de uma hora/aula, sob supervisão da pesquisadora/autora. (Anexo 1).

Por ser um estudo não-experimental, este trabalho não apresentou risco nenhum aos participantes do estudo. O projeto foi aprovado no comitê de ética e pesquisa da Universidade Luterana do Brasil. Foi entregue aos pais o Consentimento Livre e Esclarecido.

O cálculo do tamanho da amostra foi realizado no programa PEPI (Programs for Epidemiologists) versão 4.0. Considerando uma população de 407 alunos matriculados entre a sétima e oitava séries, um nível de confiança de $95 \%$, uma proporção de $50 \%$ (fornece a maior variabilidade) e uma margem de erro de $5 \%$, obteve-se um total mínimo de 198 alunos.

Após a revisão e digitação dos questionários, os dados foram inseridos em um banco de dados, utilizandose programa SPSS 10.0.

As idades dos adolescentes e de início da vida sexual foram descritas por meio de média e desvio padrão. As variáveis categóricas foram descritas por freqüências absolutas e relativas.

Para comparar as médias de idade de início da vida sexual entre meninos e meninas, o teste $t$-Student foi aplicado.

Para avaliar a associação entre as variáveis categóricas, os testes qui-quadrado de Pearson ou Exato de Fisher foram utilizados.

O nível de significância adotado foi de $5 \%$, sendo considerados estatisticamente significativos valores de $\mathrm{P} f$ 0,05. As análises foram realizadas no programa SPSS (Statistical Package for the Social Sciences) versão 10.0. Foi realizado um controle de qualidade dos dados digitados por meio do sorteio de alguns instrumentos, com conferência dos mesmos.

\section{Resultados}

Não houve predomínio de gênero. A média de idade foi de 14,4, \pm 1,39 anos. Em relação à cor, houve predomínio dos brancos. Quanto ao estado civil, a grande maioria revelou ser solteira. Com respeito às suas crenças, $44,3 \%$ são católicos, $24 \%$ não têm religião, 29,9\%, evangélicos, 10,9\% responderam outras religiões não caracterizadas, conforme demonstrado na Tabela 1.

Em relação ao questionamento sobre o conhecimento de DSTs pelos adolescentes, 77,4\% responderam que conhecem; $20,8 \%$, que não, e 1,8\% não respondeu. Ao analisar a diferença entre os gêneros, não houve significância estatística entre o conhecimento de meninas e meninos. Dentre as mais conhecidas relataram, com $91,2 \%$, Aids; $66,7 \%$, sífilis; $64,3 \%$, gonorréia e $28,7 \%$, condiloma acuminado. Houve diferença significativa sobre o conhecimentos de sífilis $(\mathrm{P}=0,02)$ e condiloma acuminado $(\mathrm{P}$ $=0,042)$ das meninas em relação aos meninos (Gráfico 1).

A quase totalidade da amostra $(93,7 \%)$ respondeu que sabe o significado de DST, não havendo diferença estatística entre os gêneros, como mostra a Tabela 2.

Questões de múltipla resposta e os percentuais foram calculados em relação ao total de indivíduos que responderam que sabem sobre a questão; ${ }^{a}$ Valor obtido pelo teste qui-quadrado de Pearson; ${ }^{\mathrm{b}}$ Valor obtido pelo Teste Exato de Fisher.

Pode-se evidenciar, na Gráfico 2, que a grande maioria dos alunos recebe informações a cerca de DST na escola.

A Tabela 2 demonstra a análise sobre o conhecimento da população de risco para DST. Houve diferença estatística $(\mathrm{P}=0,034)$ sobre as meninas em relação aos meninos, em relação à atividade sexual desprotegida.

O local mais freqüente onde os adolescentes obtêm preservativos masculinos são as farmácias, com 58,3\%, seguido com $57,6 \%$ pela unidade básica de saúde.

Mostrou que 78,3\% das meninas obtêm preservativos na farmácia, sendo que, dos meninos, 45,9\% havendo diferença estatística das meninas em relação aos meninos, com um $\mathrm{P}=0,003$.

Ao serem questionados sobre a ocorrência de DST, 
Tabela 1. Caracterização sociodemográfica da amostra

\begin{tabular}{|c|c|}
\hline Características & $\begin{array}{l}N=221 \\
\mathrm{n}(\%)\end{array}$ \\
\hline Idade (anos) - Média +/-DP & $14,4+/-1,39$ \\
\hline $12-15$ & $169(76,5)$ \\
\hline $16-19$ & $50(22,6)$ \\
\hline Não há resposta & $2(0,9)$ \\
\hline \multicolumn{2}{|l|}{ Sexo } \\
\hline Masculino & $109(49,3)$ \\
\hline Feminino & $112(50,7)$ \\
\hline \multicolumn{2}{|l|}{ Cor } \\
\hline Branca & $166(75,1)$ \\
\hline Não-Branca & $54(24,4)$ \\
\hline Não há resposta & $1(0,5)$ \\
\hline \multicolumn{2}{|l|}{ Estado Civil } \\
\hline Solteiro & $186(84,2)$ \\
\hline Casado & $4(1,8)$ \\
\hline Separado & $1(0,5)$ \\
\hline Outro & $27(12,2)$ \\
\hline Não há resposta & $3(1,4)$ \\
\hline \multicolumn{2}{|l|}{ Religião } \\
\hline Católica & $98(44,3)$ \\
\hline Evangélica & $44(19,9)$ \\
\hline Outra & $24(10,9)$ \\
\hline Não têm & $53(24,0)$ \\
\hline Não há resposta & $2(0,9)$ \\
\hline
\end{tabular}

Tabela 2. O que significa DST?

\begin{tabular}{|c|c|c|c|c|}
\hline Questões & $\begin{array}{c}\text { Amostra } \\
\text { total } \\
(n=221)\end{array}$ & $\begin{array}{c}\text { Masculino } \\
(\mathrm{n}=109) \\
\mathrm{n}(\%)\end{array}$ & $\begin{array}{c}\text { Feminino } \\
(n=112) \\
n(\%)\end{array}$ & $P$ \\
\hline \multicolumn{5}{|l|}{ O que significa DST? } \\
\hline Sabem & $207(93,7)$ & $100(91,7)$ & $107(95,5)$ & $0,378^{\mathrm{a}}$ \\
\hline $\begin{array}{l}\text { É doença que se pega } \\
\text { principalmente pelo sexo* }\end{array}$ & $188(90,8)$ & $90(90,0)$ & $98(91,6)$ & $0,877^{\mathrm{a}}$ \\
\hline $\begin{array}{l}\text { É doença venérea, da rua, } \\
\text { do mundo, e que se pega } \\
\text { apenas por intermédio } \\
\text { de profissionais do sexo. }\end{array}$ & $36(17,4)$ & $17(17,0)$ & $19(17,8)$ & $1,000^{a}$ \\
\hline Não sabem & $14(6,3)$ & $9(8,3)$ & $5(4,5)$ & $0,378^{a}$ \\
\hline
\end{tabular}

DSTs: Doenças sexualmente transmissiveis. 
Tabela 3. Quem pode pegar uma DST?

\begin{tabular}{|c|c|c|c|c|}
\hline Quem pode pegar uma DST? & Amostra & Masculino & Feminino & $P$ \\
\hline Sabem & $188(85,1)$ & $90(82,6)$ & $98(87,5)$ & $0,391^{\mathrm{a}}$ \\
\hline $\begin{array}{l}\text { Qualquer pessoas que tem } \\
\text { relação sexual com mais de } \\
\text { um parceiro, sem a proteção } \\
\text { da camisinha* }\end{array}$ & $119(63,3)$ & $61(67,8)$ & $58(59,2)$ & $0,285^{\mathrm{a}}$ \\
\hline $\begin{array}{l}\text { Somente aqueles que freqüentam } \\
\text { casas noturnas e têm sexo com } \\
\text { várias pessoas* }\end{array}$ & $18(9,6)$ & $10(11,1)$ & $8(8,2)$ & $0,661^{a}$ \\
\hline $\begin{array}{l}\text { Qualquer pessoa, cujo(a) } \\
\text { companheiro(a) sexual, tem } \\
\text { relações sexuais desprotegidas* }\end{array}$ & $112(59,6)$ & $46(51,1)$ & $66(67,3)$ & $0,034^{\mathrm{a}}$ \\
\hline Não sabem & $31(14,0)$ & $18(16,5)$ & $13(11,6)$ & $0,391^{\mathrm{a}}$ \\
\hline Não responderam & $2(0,9)$ & $1(0,9)$ & $1(0,9)$ & $0,391^{\mathrm{a}}$ \\
\hline
\end{tabular}

Tabela 4. Início das relações sexuais:

\begin{tabular}{|c|c|c|c|c|}
\hline Você já teve DST? & $\begin{array}{c}\text { Amostra } \\
\text { total } \\
(n=221)\end{array}$ & $\begin{array}{c}\text { Masculino } \\
(\mathrm{n}=109) \\
\mathrm{n}(\%)\end{array}$ & $\begin{array}{c}\text { Feminino } \\
(n=112) \\
n(\%)\end{array}$ & $P$ \\
\hline \multicolumn{5}{|l|}{ 1. Já iniciou as relações sexuais? } \\
\hline Sim & $66(29,9)$ & $41(37,6)$ & $25(22,3)$ & $0,004^{a}$ \\
\hline Não & $148(67,0)$ & $62(56,9)$ & $86(76,8)$ & \\
\hline Não responderam & $7(3,2)$ & $6(5,5)$ & $1(0,9)$ & \\
\hline $\begin{array}{l}\text { Idade de início das relações } \\
\text { sexuais - média +/- DP }\end{array}$ & $13,8+/-1,32$ & $13,3+/-1,06$ & $14,8+/-1,19$ & $<0,001^{\mathrm{c}}$ \\
\hline $11-12$ & $8(12,1)$ & $8(19,5)$ & $0(0,0)$ & $<0,001^{\mathrm{a}}$ \\
\hline $13-15$ & $45(68,2)$ & $30(73,2)$ & $15(60,0)$ & \\
\hline $16-17$ & $7(10,6)$ & $0(0,0)$ & $7(28,0)$ & \\
\hline Não responderam & $6(9,1)$ & $3(7,3)$ & $3(12,0)$ & \\
\hline
\end{tabular}


Gráfico 1. DSTs mais conhecidas pelos adolescentes:

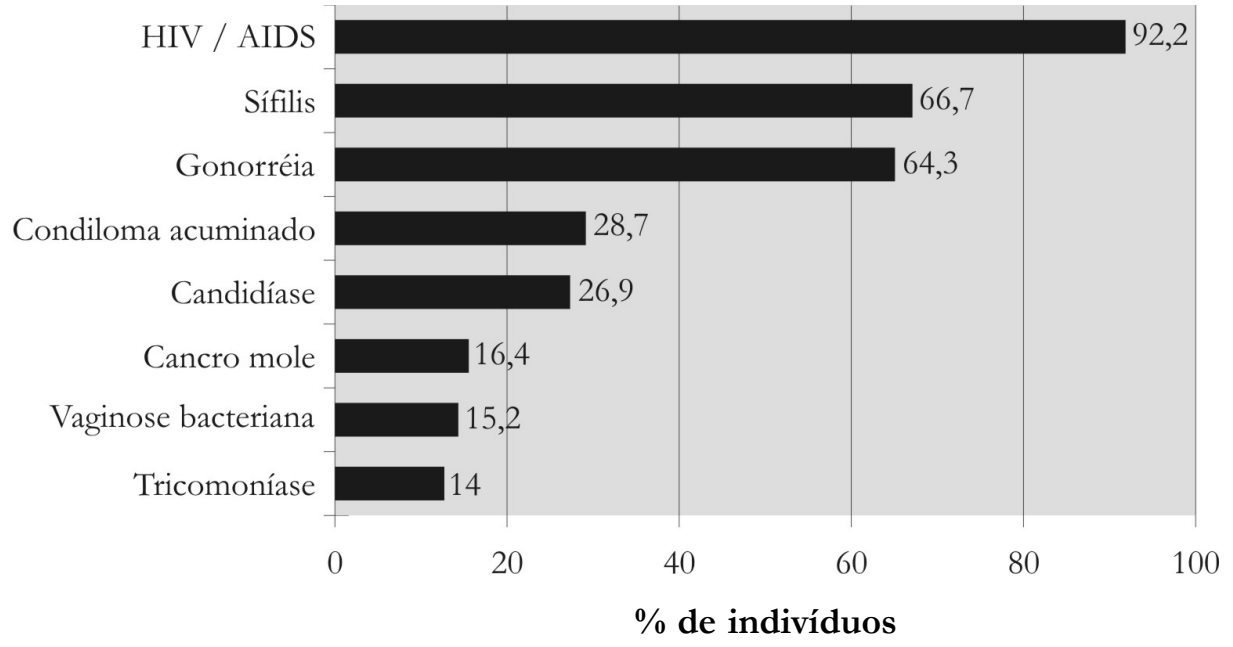

Gráfico 2. Como recebeu informações sobre DST?

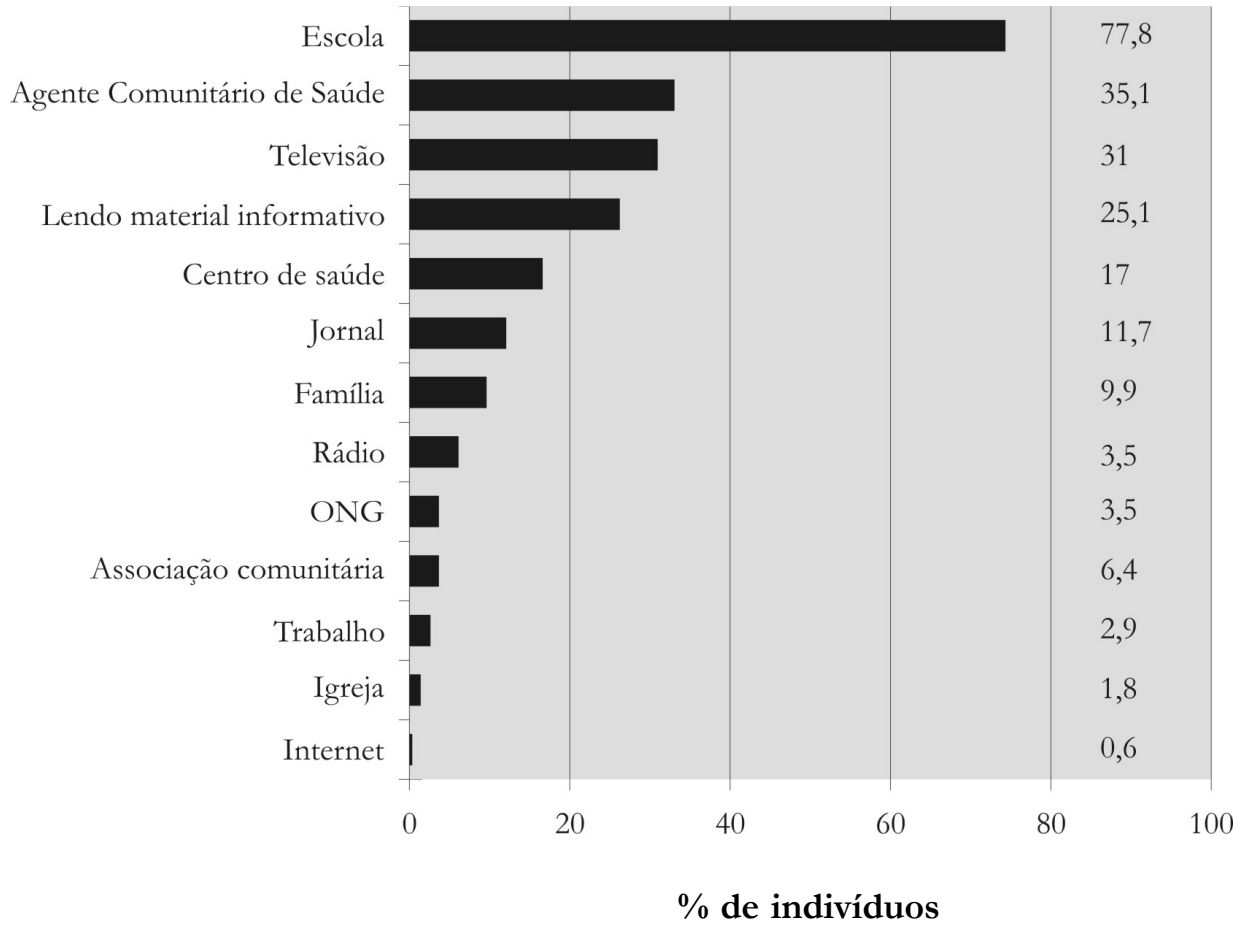


observou-se que apenas um aluno referiu a doença no passado. Não houve diferença significativa entre meninos e meninas.

Pode-se evidenciar por meio deste estudo que $90,9 \%$ da amostra faz uso do preservativo masculino e $4,5 \%$ não usa, $1,5 \%$ nunca usou e $3 \%$ não responderam; não houve diferença estatística entre meninos e meninas.

De um modo em geral, a quase totalidade $(99,5 \%)$ dos alunos referiu saber para que serve a camisinha.

Quando os adolescentes foram interrogados sobre a importância do uso da camisinha, revelou-se uma maior preocupação por parte das meninas em relação à prevenção da gravidez (85,7\% x 68,5\%), havendo diferença estatística entre os gêneros $(P=0,004)$.

Com respeito à interferência da camisinha masculina no prazer, observou-se que 33,5\% responderam que diminui e $60,6 \%$ revelaram que não. Ao analisar as diferenças entre os gêneros, constatou-se que $22,3 \%$ das adolescentes responderam que diminui o prazer, enquanto que $45 \%$ dos meninos referiram que diminui $(P<0,001)$.

Quando questionados a respeito do não-uso da camisinha pelo parceiro, 19,3\% dos meninos transariam mesmo assim e, as meninas, apenas $0,9 \%(P<0,001)$.

Os dados apresentados na Tabela 4 mostram que dos adolescentes entrevistados, 29,9\% já iniciaram as relações, $67 \%$ não e $3,2 \%$ não responderam. Ao se comparar os meninos com as meninas, observou-se uma precocidade maior entre os meninos $37,6 \%$ x 22,3\% já iniciaram as relações sexuais), sendo estatisticamente significativo $(P<0,001)$.

A média de idade do início das relações sexuais da amostra foi de 13,8 \pm 1,32 anos, sendo que os meninos tiveram uma média de 13,3 $\pm 1,06$ anos e as meninas de $14,8 \pm 1,19$ anos $(P<0,001)$.

\section{Discussão}

No Brasil, em torno de 19\% da população geral é constituída de adolescentes que, segundo o censo de 2000, encontram-se em torno de 34 milhões ${ }^{12}$.

Durante a adolescência, ocorrem importantes mu- danças biopsicossociais, tais como a maturação dos caracteres sexuais secundários; independência socioeconômica e emocional dos pais; elaboração da identidade pessoal e sexual; aquisição do pensamento abstrato; exercício da sexualidade, intimidade e afetividade ${ }^{13}$.

A vida sexual é freqüentemente iniciada mais cedo, quando passam a não dar importância à virgindade e a considerar o sexo tão importante para homens quanto para mulheres. Por outro lado, muitos não se protegem contra DSTs e Aids, correndo o risco também de uma gravidez precoce $^{14}$.

Os achados neste trabalho mostraram que existe um ótimo conhecimento de DST, já que neste estudo 93,7\% dos adolescentes mostraram conhecimentos sobre essas doenças em números bastante superiores ao encontrado em outros trabalhos realizados em escolas públicas, como, por exemplo, o de Martins $e t a l .^{15}$, que demonstraram, em seu trabalho, comparando escolas públicas e privadas, que $80,1 \%$ dos alunos da escola pública atingiram um escore de conhecimento considerado adequado, enquanto que, na escola privada, 90,7\% atingiram o conhecimento adequado.

Quando os adolescentes foram indagados sobre o conhecimento a respeito das DSTs, a mais citada foi Aids, seguida de sífilis e gonorréia. Ao se comparar os meninos e as meninas, observou-se um conhecimento maior de sífilis e condiloma por parte das meninas. Por outro lado, no estudo de Romero ${ }^{13}$ et all, a doença mais conhecida também foi a Aids (39\%), enquanto as outras doenças foram pouco referidas.

É importante lembrar que o fato dos alunos conhecerem uma doença pode apenas significar ter ouvido falar ou visto em campanhas; sendo que, muitas vezes, estes conceitos podem não ser bem esclarecidos ou confirmados. Portanto, é vital a existência de um programa de esclarecimento entre os adolescentes, quer seja na escola ou na comunidade.

A primeira relação sexual é considerada um marco na vida reprodutiva de qualquer indivíduo e tem ocorrido cada vez mais precocemente. $\mathrm{Na}$ maioria das vezes, a iniciação sexual de jovens do sexo masculino ocorre antes 
que a de jovens do sexo feminino, fato esperado em uma cultura que tradicionalmente tem estimulado os jovens do sexo masculino a iniciarem suas práticas sexuais bem mais cedo do que o sexo feminino ${ }^{16}$.

Vários estudos demonstram que mais da metade das adolescentes têm a primeira relação sexual com idade menor ou igual aos 15 anos $^{17,18,19,14}$.

Em contrapartida, Martins et all ${ }^{5}$, em seu estudo, demonstrou que a idade da primeira relação foi aproximadamente 17,5 anos, nos alunos de escolas publicas. Verificou, também, que a iniciação, principalmente em idades mais tardias, motiva os adolescentes à busca ativa de mais informações sobre métodos anticoncepcionais.

No presente trabalho, os achados são semelhantes à maioria dos estudos, em que a média de início das relações esteve entre 11 e 15 anos.

Observou-se uma significativa diferença entre homens e mulheres em relação ao início das relações sexuais, sendo que, na idade de 11 a 12 anos, 19,5\% dos meninos já teriam iniciado a atividade sexual, diferentemente das meninas que começaram numa idade mais tardia, isto é, aos 13 anos.

Borges e Schor ${ }^{16}$, em um estudo transversal realizado em São Paulo, mostraram que a primeira relação sexual ocorreu em média aos 15,13 anos de idade. Não foi observada diferença estatisticamente significativa entre a idade média de início da vida sexual entre homens e mulheres (14,94 e 15,29 anos, respectivamente). Por outro lado, no estudo do Dr. Almeida et al ${ }^{20}$, foi demonstrado que os homens iniciaram sua vida sexual mais precocemente que as mulheres, com idade mediana de 13 e 15 anos, respectivamente.

Trajman $e t a l^{10}$, em seu estudo, obteve uma mediana de 15 anos de idade para início das relações sexuais dos adolescentes, sendo as meninas com média de 15,2 anos e os meninos com 14,2, obtendo ainda que, entre os meninos, $15 \%$ já haviam iniciado relações antes dos 11 anos, contrastando com as meninas, que ainda não haviam iniciado.

Segundo o MS existem mais homens sexualmente ativos entre 14 e 19 anos do que mulheres, com cifras de $8,5 \%$ e $5,1 \%$, respectivamente ${ }^{16}$.

Estudos do Center for Disease Control and Prevention sobre condutas de risco dos jovens demonstram que muitos deles começam a ter relações sexuais muito cedo e que $47 \%$ dos estudantes de segundo grau já têm relações sexuais, e 7,4\% destes afirmam já ter tido relações antes dos 13 anos de idade?

Geralmente, os adolescentes estão em um processo de consolidação das atitudes e em busca da autonomia. Assim, profissionais da saúde e educadores devem ser preparados para assumir o papel de facilitadores dessas discussões.

É importante promover atividades que enfatizem a necessidade de reflexão, quanto à importância do preservativo, sobre os riscos principalmente de infectar$\mathrm{se}^{21}$.

Não há dúvida que, atualmente, as adolescentes falam mais sobre sexo com os pais. Contudo, as conversas transitam apenas na superficialidade, não há esclarecimento sobre a necessidade de alguns cuidados antes da iniciação sexual e do conhecimento adequado dos métodos contraceptivos $^{13}$.

No presente estudo a grande maioria dos adolescentes $(90,9 \%)$ referiu fazer uso do preservativo masculino. Estes dados se contrapõem aos do estudo de Vieira et al ${ }^{19}$, nos quais somente $20,5 \%$ das adolescentes referiam o uso consistente do preservativo.

Também, Taquete et al. ${ }^{9}$, em seu estudo, evidenciaram que, em geral, os adolescentes, apesar de saberem que o preservativo evita doenças e gravidez, mesmo assim não o usam, existindo uma lacuna entre o nível de conhecimento e o uso efetivo da camisinha; $46 \%$ dos meninos nunca ou às vezes usa e $54 \%$ quase sempre ou sempre usa. Entre as meninas, $64,5 \%$ nunca ou às vezes usa e $35,5 \%$ sempre ou quase sempre usa.

Da mesma forma, Trajman et al ${ }^{10}$, em seu estudo mostraram que $94 \%$ dos adolescentes conheciam a proteção oferecida pelo preservativo, porém somente $34 \%$ faziam uso sempre. 
Ao analisar os dados, constatou-se que as meninas demonstraram uma maior preocupação em relação à atividade sexual desprotegida e ao uso da camisinha para prevenir gravidez. Também, referiram não manter relação sexual se o parceiro recusasse usar camisinha. Estes achados nos levam a refletir se está ocorrendo, nesta população, uma mudança sobre o modelo tradicional dos valores na questão de gênero, em que ocorre uma supremacia masculina. Tradicionalmente, ser mulher significa submissão, passividade e temor em relação ao homem, tornando-as mais vulneráveis às DSTs ${ }^{22}$.

Neste estudo, pode-se evidenciar que os adolescentes obtêm informações a respeito das DST, na grande maioria, nas escolas, seguida de agentes comunitários de saúde e na televisão. Romero et al ${ }^{13}$ demonstraram que as principais fontes de informação sobre sexualidade para as adolescentes, nas zonas rural e urbana em Guararema, São Paulo, foram os pais e as amigas, não havendo diferença estatística entre as zonas, e houve poucos relatos de busca aos profissionais da saúde.

Segundo Werthein et al ${ }^{14}$ deve-se fazer uma reflexão sobre a necessidade de se repensar as políticas públicas de apoio aos jovens nos campos da educação, da saúde, da assistência social, dos direitos humanos e da cidadania. Por trás dos números impactantes relacionados aos jovens, existe significativa falta de informação por parte dos pais e professores e despreparo das escolas; um terço dos pais ouvidos não dialoga com os filhos sobre o tema; $40 \%$ não têm conhecimento sobre DST; e $27 \%$ dos professores não têm informações suficientes sobre o assunto. As conversas sobre sexo costumam estar restritas as aulas de ciência e biologia.

\section{Considerações Finais}

Pode-se concluir com este trabalho que grande maioria dos adolescentes demonstrou conhecimento adequado sobre DSTs.

O grau de informação da amostra em estudo revelou números que podem se comparar com escolas privadas demonstradas em outros trabalhos.
Na obtenção de informações sobre DSTs, a escola mostrou ser o maior veículo de informação, os agentes comunitários, o segundo, mostrando a importância fundamental em valorizarmos a escola e principalmente $o$ papel fundamental do professor.

A grande maioria faz uso do preservativo masculino. As meninas dão mais importância para o risco de gravidez.

As meninas demonstraram ter mais consciência do uso do preservativo, mostrando que os meninos têm maior resistência ao uso da camisinha, havendo, quem sabe, a necessidade de maior conscientização dos meninos ao uso da camisinha, isso talvez represente uma questão sociocultural.

Os meninos iniciam as relações sexuais mais precocemente que as meninas.

Neste estudo, observou-se um elevado conhecimento sobre DST/Aids e do uso da camisinha. Pode-se inferir que isso se deva ao fato de que esta escola possui um programa de educação sexual e cidadania para adolescentes, havendo, possivelmente, a troca de informações entre os adolescentes.

Demonstrou-se, com este trabalho, a importância da realização, nas escolas, de projetos que trabalhem a educação sexual.

Dessa forma, este estudo demonstra uma necessidade de abordagem mais incisiva em relação aos adolescentes do sexo masculino, por uma questão sociocultural dos parâmetros sociais. 
ANEXO 1

PARTE I

DADOS PESSOAIS

1. Sexo:

( ) Masculino

( ) Feminino

2. Idade: anos

3. Cor: ( ) Branca

( ) Não-Branca

4. Religião: ( ) Católica

( ) Evangélica ( ) Não Tem

( ) Outra

5. Estado civil: ( ) Solteiro ( ) Casado ( ) Viúvo

( ) Separado

( ) Outro

\section{PARTE II \\ PERGUNTANDO SOBRE DST}

\section{O que significa Doenças Sexualmente Transmissíveis (DSTs)?}

-) Não sei

É doença que se pega principalmente pelo sexo.

) É doença venérea, da rua, do mundo, e que se pega apenas com profissionais do sexo (como, por exemplo, prostitutas).

\section{Quem pode pegar uma DST (Doença Venérea)?}

(___ Não sei

(___ Q Qualquer pessoa que tenha relação sexual com mais de um parceiro, sem a proteção da camisinha.

(___ Somente aqueles que freqüentam casas noturnas (como, por exemplo, cabarés e casas de shows eróticos) e fazem sexo com várias pessoas.

(___ ) Qualquer pessoa, cujo companheiro ou companheira sexual tenha relações sexuais desprotegidas (sem camisinha).

3. Para que serve a camisinha?

(___ Não sei

(___ Para evitar as Doenças Venéreas (as DSTs).

(___ Para proteger do vírus da Aids (o HIV).

(___ Para evitar gravidez.

4. Você acha que a camisinha masculina diminui o prazer na relação sexual?

( ) $\operatorname{Sim}($ ) Não

5. Os adolescentes devem usar a camisinha em todas as relações sexuais?

( ) $\operatorname{Sim}($ ) Não

6. Se o parceiro não quiser usar camisinha, transaria com ele mesmo assim?

( ) $\operatorname{Sim}(\quad)$ Não

7. Ter uma DST aumenta as chances de se pegar outra DST e o vírus da AIDS?
(___ Não sei
) $\operatorname{Sim}$
Não

8. Você conhece alguma Doença Sexualmente Transmissível (DST)?

(__ $)$ Sim (_) Não

9. Se você disse SIM, informe quais das DST abaixo você conhece:

(__ Sífilis (_ Cancro mole (_ Condiloma acuminado (verrugas genitais ou crista de Galo) 
(__ Gonorréia (_ (_) Tricomoníase (_) Candidíase

(___ Vaginose bacteriana (_) HIV/AIDS

(___ Outra(s)

10. Onde você recebeu informações sobre DST?

) Por intermédio de Agente Comunitário de Saúde (_ No Centro de Saúde

) Pelo Rádio (_ _ Pela Televisão (_) Pelo Jornal

) Lendo material informativo (_) Na Igreja

) Na Escola (_ No Trabalho

_) Na Associação Comunitária (_ Por intermédio do pessoal da ONG (Organização Não-

Governamental) (_) Em outra fonte. Especifique:...

11. O adolescente portador do vírus da DST/Aids deve continuar indo a escola?

( ) $\operatorname{Sim}(\quad)$ Não

\section{PARTE III}

12. Já iniciou as relações sexuais:

$\operatorname{Sim}() \operatorname{com}$ _anos_ Não $($ )

Se você respondeu NÃO para a questão acima, o questionário termina aqui.

13. Você usa camisinha?

(__ Nunca usei (_ (_) Não uso, porque não sei como usar.

(__ Não uso, porque não gosto. (_ _ Não uso, porque não confio nela.

(___ Não uso, porque não sei onde conseguir a camisinha.

(___ Uso apenas quando transo com algumas pessoas, para evitar DST.

(___ Uso para evitar gravidez. (_ _ Sempre uso nas minhas relações sexuais.

14. Se você usa camisinha, como você consegue obtê-las?

(__ Com os Agentes Comunitários de Saúde. (_ No Posto de Saúde Pública.

(__ Na Farmácia. (_ _ No Supermercado.

(__ ) Na Associação Comunitária. (_ Com pessoas de Organizações Não-Governamentais (ONGs).

(___ Em outra fonte. Qual?

15. Você já teve uma DST?

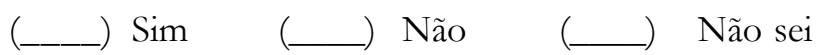

Se você disse SIM, responda:

16. Você sabe qual foi a DST que você teve?
) Não
) Sim - Escreva o(s) nome(s).

17. Como você se tratou de sua(s) DST(s)?

) Orientado(a) por médico no posto de saúde. (_ Orientado(a) pelo balconista da farmácia.

_) Orientado(a) por amigo, parente (ou outra pessoa do meu convívio). (__ Por minha própria conta.

18. Seu parceiro (companheiro ou companheira) sexual também foi tratado(a) quando você teve a(s) DST(s)? (__ $)$ Sim (_ $)$ Não

19. Você continuou tendo relações sexuais quando estava com DST?

) $\operatorname{Sim}$ Não 


\section{Referências}

1. DeCherney AH, Nathan L. Current - Obstetrícia e Ginecologia. 9 ed. 2005. 200p.

2. Freitas F, Menke CH, Rivoire W, Passos EP. Rotinas em Ginecologia. 4 ed. Porto Alegre (RS): Artmed; 2001. p. 112133.

3. Global prevalence and incidence of selected curable sexually transmitted infections. Geneva: World Health Organization; 2001. Sexualy transmitted infections, World Health Organition. Disponível em: http:// www.wpro.who.int/health_topics/sexually_transmitted _infections / general_info.htm Acesso em: 04 ago. 2007. 4. Duncan BB, Schimidt MI, Giugliani ERJ. Medicina ambulatorial - condutas de atenção primária baseada em evidencias. 3 ed. Porto Alegre (RS): Artmed; 2004. p. 127583.

5. Torres GV, Davim RMB, Almeida MCS. Conhecimento e opiniões de um grupo de adolescentes sobre a prevenção de AIDS. Revista Latino Americana de Enfermagem. Abr. 1999; 7(2):41-46.

6. Paiva V, Venturi Júnior FI, Lopes F. Ministério da Saúde. Uso de Preservativos Pesquisa Nacional MS/IBOPE, Brasil 2003. Disponível em: http://www.aids.gov.br. Acesso em: 1 ago. 2007.

7. Center for disease control and prevention, 2006. Disponível em: http://www.cdc.gov/hiv/topics/aa/resources/ factsheets/aa.htm. Acesso em: 30 ago. 2007

8. Arruda S, Cavasin S. Comportamento da população sexualmente ativa. Ministério da Saúde, Programa Nacional DST/AIDS, Boletim (3).

9. Taquete SR, Vilhena MM, De Paula MC. Doenças sexualmente transmissíveis e gênero: um estudo transversal com adolescentes no Rio de Janeiro. Caderno Saúde Pública. Jan.-Fev. 2004; 20(1): 282-90.

10. Trajman A, Belo MT, Teixeira EG. et al. Conhecimento sobre DST/AIDS e comportamento sexual entre estudantes do ensino médio no Rio de Janeiro, Brasil. Caderno Saúde Pública. Jan./Fev. 2003; 19(1): 127-33.

11. Questionário instrumento de coleta de dados. Disponível em: http://www.aids.gov.br/assistência/pacs/pacs_psf_10.htm.
Acesso em: 08 ago. 2006.

12. IBGE. Disponível em: http://www.ibge.gov.br. Acesso em: 03 abr. 2007.

13. Romero KT, Medeiros EHGR, Vitale MSS, Wheiba J. O conhecimento das adolescentes sobre questões relacionadas ao sexo. Rev Assoc Med Bras. 2007; 53 (1): 14-9.

14. Wherthien J. Juventude aponta novos rumos para políticas de juventude, 2004. Disponível em: http:// www.uneso.org.br/noticias/opnião/artigow2004/ politicasjuventude/mostra documento. Acesso em: 05 ago. 2007.

15. Martins LBM, Costa Paiva LH, Osis MJD, Souza MH, Neto AMP, Tadini V. Fatores associados ao uso de preservativo masculino e ao conhecimento sobre DST/ AIDS em adolescentes de escolas públicas e privadas do Município de São Paulo,Brasil. Caderno Saúde Pública, Rio de Janeiro. Fev. 2006; 22(2): 315-23.

16. Borges ALV, Schor N. Início da vida sexual na adolescência e relações de gênero: um estudo transversal em São Paulo, Brasil, 2002. Cadernos Saúde Pública. Mar.-Abr. 2005; 21(2): 499-507.

17. Leite IC, Rodrigues RN, Fonseca MC. Fatores associados com o comportamento sexual e reprodutivo entre adolescentes das regiões Sudeste e Nordeste do Brasil. Cadernos de Saúde Pública. Mar.-Abr. 2005; 20(2): 474-81. 18. Roche RG, Alfaro AC, Aguilera LEV, Sanchez MH, Valera AM. Comportamiento sexual y uso del preservativo em adolescentes y jóvenes de um área de salud. Rev Cubana Med Gen Integr. 2006; 22(1).

19. Vieira MAS, Guimarães BEM, Barbaso MA, Turchi MD, Alves MFC, Seixas MSC, Garcia MMD, Minamisava R. Fatores associados ao uso de preservativo em adolescentes do gênero feminino no município de Goiânia. J Bras Doença Sex Transm. 2004; 16(3): 77-83.

20. De Almeida MCC, Aquino EML, Gaffkin L, Magnani RI. Uso de contracepção por adolescentes em escolas públicas na Bahia. Rev Saúde Pública. 2003; 3(5): 566-75.

21. Jimenez AL, Gotlieb SLD, Hardy E, Zaneveid LJD. Prevenção de doenças sexualmente transmissíveis em mulheres: associação com variáveis socioeconômicas e 
demográficas. Cadernos de Saúde Pública. Jan.-Fev. 2001;

17(1): 55-62.

22. Paiva V, Bugamelli L, Leme B, Ventura FE, Tunala L, Santos N. A vulnerabilidade das mulheres ao HIV é maior por causa dos condicionantes de gênero. Disponível em: http://www. usp.br/nepaids. Acesso em: 04 set. 2007.

\section{Endereço para correspondência:}

Caroline Reis Gerhardt

Rua Vicente da Fontoura, 3007 - apt. 304

Porto Alegre - Rio Grande do Sul

CEP: 90640-003

\section{Endereço eletrônico:}

vrcerg@hotmail.com 